\title{
Symmetric Trilayer Dielectric Composites with High Energy Density Using Low Loading of $\mathrm{KNbO}_{3}$ Nanosheets
}

Yuan Liu, Hang Luo*, Di Zhai, Ru Guo, Xuefan Zhou, Zhida Xiao, Haoran Xie, Dou Zhang*

Powder Metallurgy Research Institute, Central South University, Changsha 410083, China

*Corresponding author Email:

hangluo@csu.edu.cn (Hang Luo)

dzhang@csu.edu.cn (Dou Zhang)

Total number of pages: 10

Total number of figures: 5

Total number of tables: 2 


\section{Characterization}

X-ray diffraction analysis was performed using Rigaku D-Max/2550VB+ $(\mathrm{Cu} \mathrm{K \alpha}$ radiation $\lambda=1.5418 \AA$ ), and the crystal structure information of $\mathrm{KN}$ nanosheets was obtained. The morphologies of KN nanosheets and KN/PVDF nanocomposite films were characterized by scanning electron microscope (SEM, JSM-6390). The microstructure of $\mathrm{KN}$ nanosheets was analyzed by high-resolution transmission electron microscope (HRTEM, Titan G260-300). Intelligent fourier infrared spectroscopy (FT-IR, Nicolet 6700) and X-ray photoelectron spectroscopy (XPS, Thermo Fisher Scientific, ESCALAB250Xi, USA) were used to characterize the surface modification of KN nanosheets. The piezoelectric response force microscope (PFM mode, Veeco, Nanoman TM VS, USA) was used to measure the ferroelectric response of the $\mathrm{KN}$ nanosheets, which were dispersed on the silicon wafer with sputtered platinum electrodes. PFM is obtained by applying a direct current (DC) voltage of $-12 \mathrm{~V}$ to $12 \mathrm{~V}$ superimposed on an $\mathrm{AC}$ modulation voltage of $41 \mathrm{kHz}$, a way from contact resonance. An impedance analyzer (Agilent, 4294A, LCR) was used to measure the dielectric constant and dielectric loss of the nanocomposite film as a function of frequency (from $1 \mathrm{kHz}$ to $10 \mathrm{MHz}$ ). At room temperature, a ferroelectric test system (Aix ACCT, TF-2000, Germany) was used to characterize the electric displacement-electric field hysteresis loops (D-E loops) of the KN/PVDF nanocomposites at $10 \mathrm{~Hz}$. 
Table S1 Table of properties summary of two e trilayer-structured nanocomposites and pure PVDF

\begin{tabular}{|c|c|c|c|c|c|c|c|c|c|}
\hline & PVDF & \multicolumn{4}{|c|}{$x-0-x$} & \multicolumn{4}{|c|}{$0-x-0$} \\
\hline samples & $10 w t \%$ & $1-0-1$ & $3-0-3$ & $5-0-5$ & $7-0-7$ & $0-1-0$ & $0-3-0$ & $0-5-0$ & $0-7-0$ \\
\hline $\begin{array}{l}\text { Dielectric constant } \\
\qquad(1 \mathrm{kHz})\end{array}$ & 9.29 & 10.76 & 11.21 & 11.89 & 13.03 & 10.13 & 10.55 & 11.26 & 11.61 \\
\hline $\begin{array}{l}\text { Dielectric loss } \\
\qquad(1 \mathrm{kHz})\end{array}$ & 0.0190 & 0.0213 & 0.0262 & 0.0289 & 0.0350 & 0.0195 & 0.0224 & 0.0262 & 0.0295 \\
\hline $\begin{array}{l}\text { Max. } \mathrm{Eb}_{\mathrm{b}} \\
(\mathrm{kV} / \mathrm{mm})\end{array}$ & 420 & 450 & 400 & 400 & 350 & 539 & 497 & 410 & 370 \\
\hline $\begin{array}{l}\text { Weibull. Eb } \\
(\mathrm{kV} / \mathrm{mm})\end{array}$ & 408.8 & 422.5 & 374.5 & 372.4 & 324.0 & 536.0 & 467.5 & 381.9 & 338.2 \\
\hline$\beta$ & 21.2 & 16.2 & 18.1 & 14.3 & 14.4 & 26.2 & 13.2 & 11.7 & 10.5 \\
\hline $\mathrm{U}_{\mathrm{dis}}\left(\mathrm{J} / \mathrm{cm}^{3}\right)$ & 9.56 & 9.44 & 8.47 & 8.35 & 8.14 & 19.97 & 13.99 & 10.44 & 8.10 \\
\hline$\eta(\%)$ & 53.13 & 47.87 & 51.81 & 46.28 & 41.69 & 53.42 & 47.62 & 48.71 & 43.44 \\
\hline$P_{\max }\left(\mu \mathrm{C} / \mathrm{cm}^{2}\right)$ & 7.594 & 6.924 & 7.288 & 7.569 & 9.229 & 12.74 & 10.13 & 8.886 & 8.255 \\
\hline $\operatorname{Pr}\left(\mu \mathrm{C} / \mathrm{cm}^{2}\right)$ & 1.66 & 1.48 & 1.91 & 2.06 & 2.80 & 2.70 & 2.44 & 1.94 & 2.25 \\
\hline $\begin{array}{c}\mathrm{P}\left(\mu \mathrm{C} / \mathrm{cm}^{2}\right) \\
\text { @350kV/mm }\end{array}$ & 5.908 & 6.489 & 6.701 & 7.438 & 9.229 & 6.456 & 6.589 & 6.798 & 7.450 \\
\hline $\begin{array}{l}\operatorname{Pr}\left(\mu \mathrm{C} / \mathrm{cm}^{2}\right) \\
\text { @ } 350 \mathrm{kV} / \mathrm{m}\end{array}$ & 1.27 & 1.68 & 1.94 & 2.09 & 2.80 & 1.21 & 1.54 & 1.38 & 1.95 \\
\hline
\end{tabular}



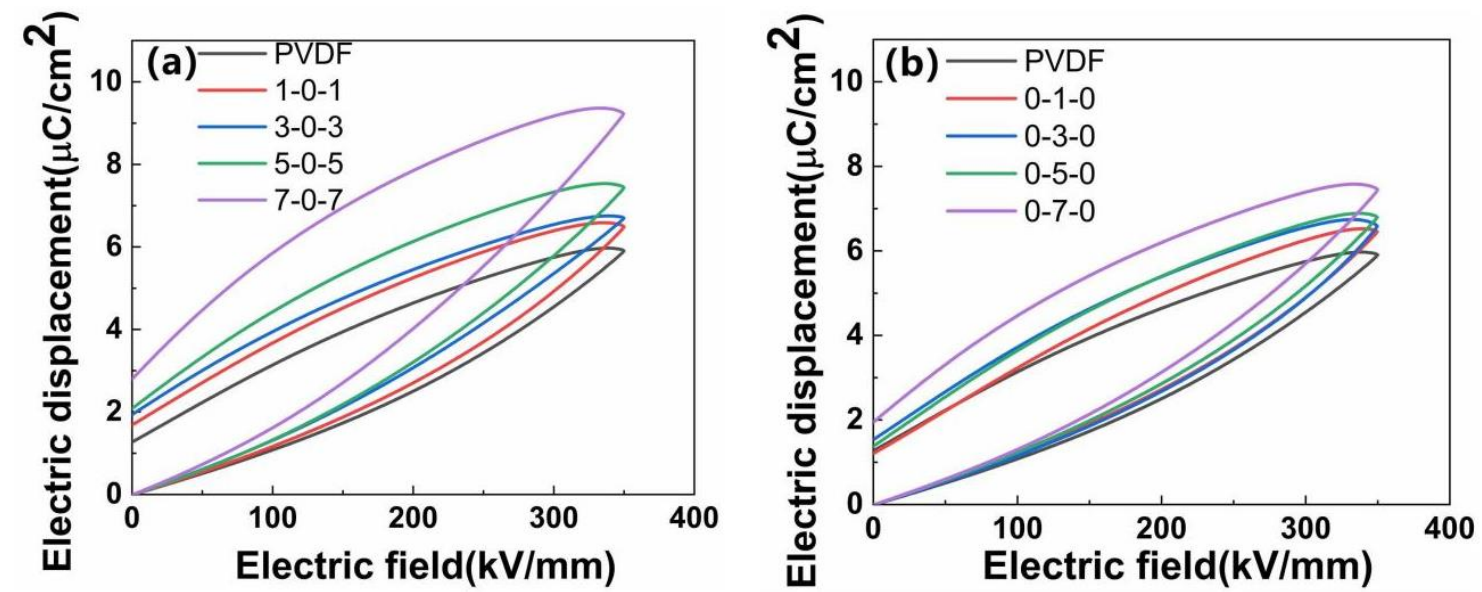

Fig. S1 D-E loops of two trilayer-structured nanocomposites at $350 \mathrm{kV} \mathrm{mm}^{-1}$ (a) $\mathrm{x}-0-\mathrm{x}$ (b) $0-\mathrm{x}-0$ 
Differential scanning calorimetry (DSC), a thermal analysis method, mainly studies the thermodynamic properties of materials, such as the glass transition temperature, melting temperature, and crystallization temperature of the material. The shape of the melting peak on the DSC curve can reflect the size of the crystal grains size distribution, and the crystallinity of the material can be calculated by the enthalpy of fusion. The melting enthalpy is the area of the curve enclosed by the melting peak of the DSC curve and the baseline, expressed by $\Delta \mathrm{H}_{\mathrm{m}}$. The melting enthalpy of the polymer is directly proportional to the crystallinity. When knowing the melting enthalpy $\Delta \mathrm{H}_{\mathrm{m}}{ }^{*}$ of a certain polymer at $100 \%$ crystallinity, where $\Delta \mathrm{H}_{\mathrm{m}}{ }^{*}$ of pure PVDF is $104 \mathrm{~J} / \mathrm{g}$, the crystallinity of other composite films can be calculated:

$$
\mathrm{X}_{\mathrm{c}}=\left(\Delta \mathrm{H}_{\mathrm{m}} / \Delta \mathrm{H}_{\mathrm{m}}{ }^{*}\right) \times 100 \%
$$

In this paper, the DSC-25 Differential Scanning Calorimetry Analyzer of American TA Company is used to test and analyze the DSC cooling curve of the pure PVDF and the corresponding nanocomposites whose heating rate is $10{ }^{\circ} \mathrm{C} / \mathrm{min}$. As shown in Figure S2, with the increase of KN nanosheets loading in the upper \& lower layers, the melting temperatures of the nanocomposites shift to the right slowly. This shows that the internal grain size of the polymer becomes larger with the loading of KN nanosheets.

The specific parameters of the calculated DSC are shown in Table S2. The melting temperatures of the nanocomposites gradually rises from $170.65{ }^{\circ} \mathrm{C}$ to $173.36{ }^{\circ} \mathrm{C}$. The increase in the melting temperature indicates that the internal grain size of the polymer becomes larger with the loading of KN nanosheets. The 0-1-0 
sample has the same crystallinity as pure PVDF, indicating that the appropriate content of $\mathrm{KNbO}_{3}$ nanosheets will not reduce the crystallinity of PVDF. The 0-7-0 sample has the smallest melting peak area, the melting enthalpy of the sample reduced to $50.760 \mathrm{~J} / \mathrm{g}$, so its crystallinity which is only $48.81 \%$ also is the smallest. In general, except for the 0-1-0 sample, the crystallinity of the other nanocomposites is lower than that of the pure PVDF, indicating that different $\mathrm{KN}$ nanosheets additive will affect the crystal size of the polymer itself.

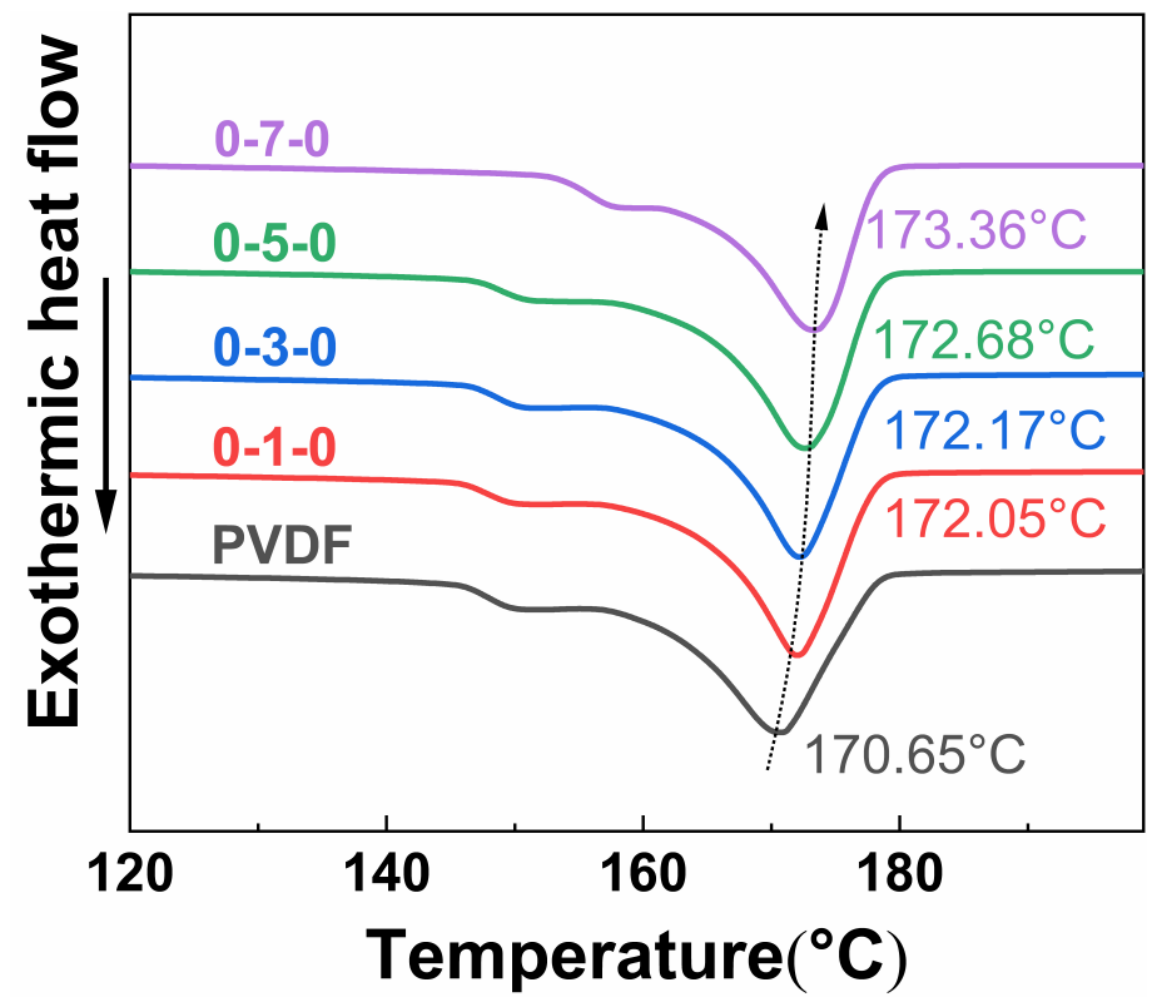

Fig. S2 DSC curve of the samples 
Table S2 Thermodynamic properties of the samples

\begin{tabular}{|c|c|c|c|}
\hline Samples & $\begin{array}{r}\text { Melting } \\
T_{\mathrm{m}}\left({ }^{\circ} \mathrm{C}\right)\end{array}$ & $\begin{array}{c}\text { Melting Enthalpy } \\
\Delta H_{\mathrm{m}}(\mathrm{J} / \mathrm{g})\end{array}$ & $\begin{array}{c}\text { Crystallinity } \\
\boldsymbol{X}_{\mathrm{c}}(\%)\end{array}$ \\
\hline PVDF & 170.65 & 59.154 & 56.88 \\
\hline $0-1-0$ & 172.05 & 59.157 & 56.88 \\
\hline $0-3-0$ & 172.17 & 58.950 & 56.68 \\
\hline $0-5-0$ & 172.68 & 58.148 & 55.91 \\
\hline $0-7-0$ & 173.36 & 50.760 & 48.81 \\
\hline
\end{tabular}


(a)

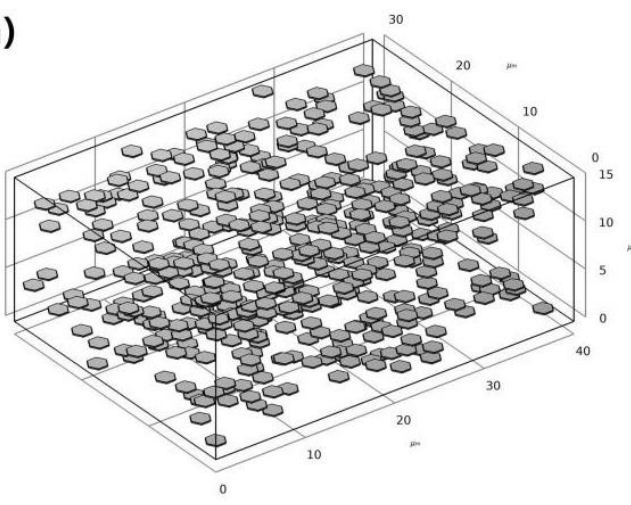

(c)

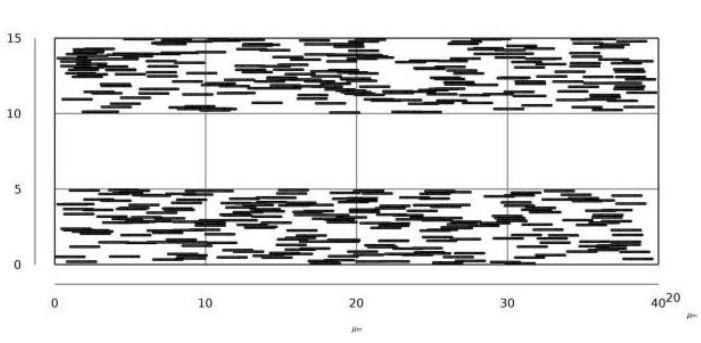

(b)

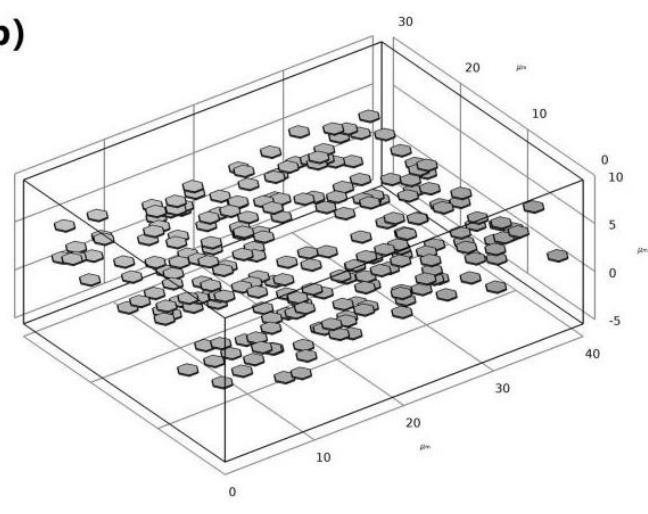

(d)

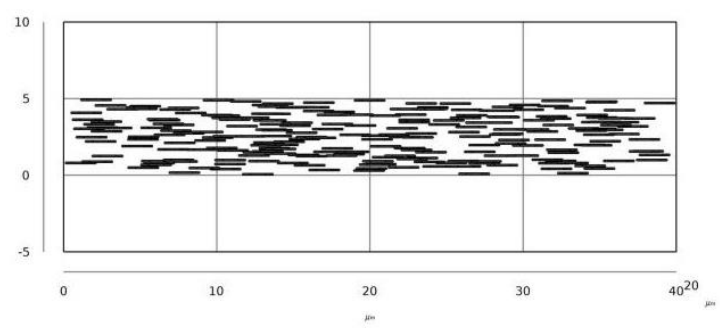

Fig. S3 Three-dimensional geometric model of (a) 1-0-1 and (b) 0-1-0 composite films; cross-section images of (c)1-0-1 and (d) 0-1-0 composite films. 

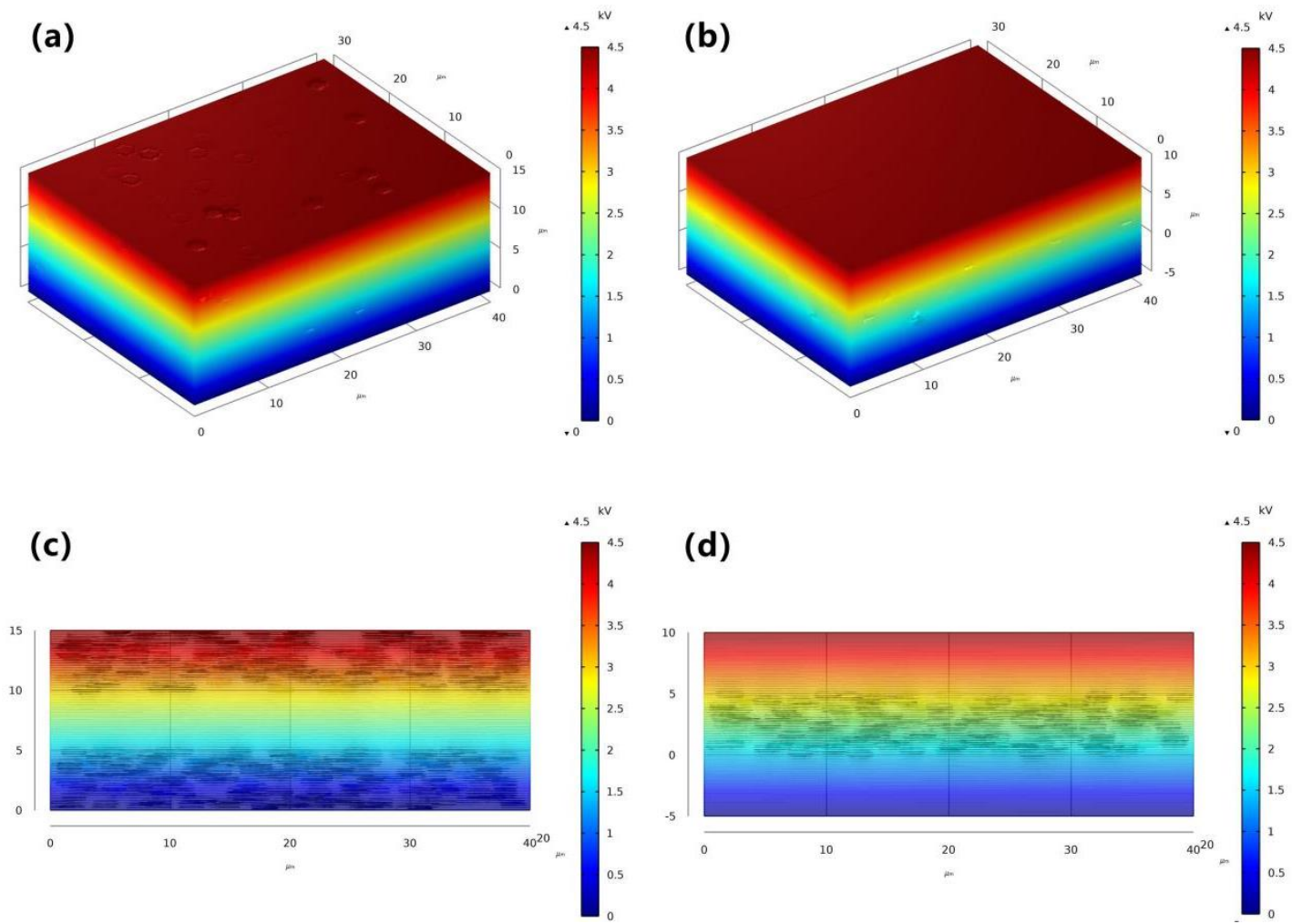

Fig. S4 The electric potential of two symmetric trilayer-structured (a) 1-0-1 and (b) 0-1-0 composite films; cross-section images of (c) 1-0-1 and (d) 0-1-0 composite films. 
(a)

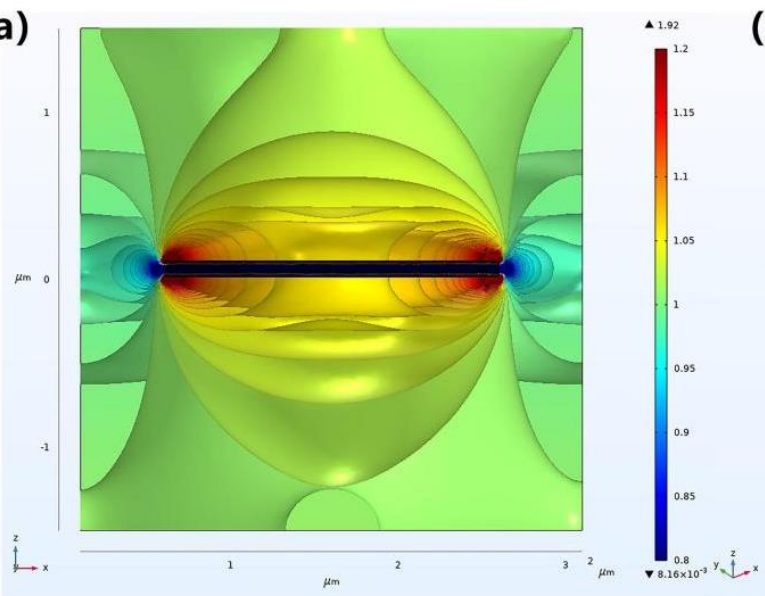

(b)

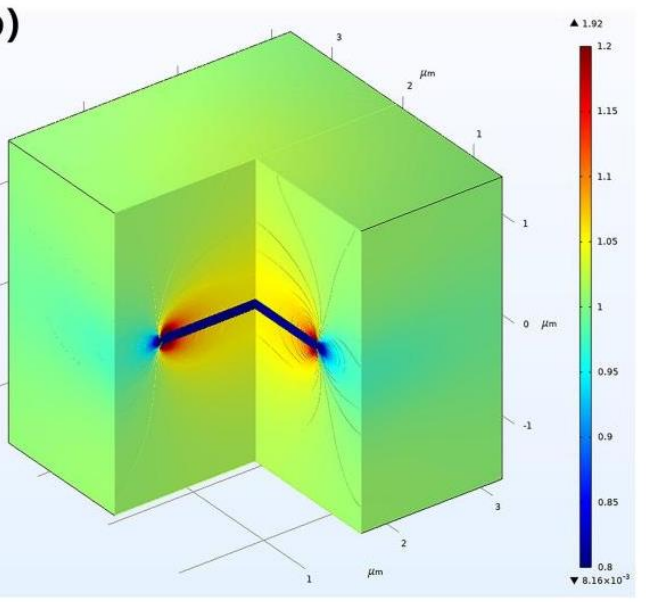

Fig. S5 Finite element simulation of (a) enlarged section and (b) partial cross-sectional with single $\mathrm{KN}$ nanosheet in 0-1-0 composite film. 